Pacific Journal of Mathematics

THE NORM OF A CERTAIN DERIVATION 


\section{THE NORM OF A CERTAIN DERIVATION}

\section{Charles A. McCarthy}

J. C. Stampfli has asked whether the norm of the derivation $\mathfrak{Q}_{T}: A \rightarrow T A-A T$ as a mapping of the subalgebra $\mathfrak{A}$ of $\mathfrak{B}(H)$ into $\mathfrak{B}(H)$ is given by $\inf \left\{2\left\|T-A^{\prime}\right\|: A^{\prime} \in \mathfrak{A}^{\prime}\right\}$. That this need not be the case is shown through an example in $4 \times 4$ matrices.

$H$ is a Hilbert space. $\mathfrak{B}(H)$ is the algebra of all bounded linear operators on $H$. $\mathfrak{A}$ is a subalgebra of $\mathfrak{B}(H)$ and $\mathfrak{U}^{\prime}$ is the commutant of $\mathfrak{i}$.

In [6], J. C. Stampfli proved that the norm of $\mathfrak{\Omega}_{T}$ as a mapping of $\mathfrak{B}(H)$ into itself is precisely $2 \inf _{\lambda}\|T-\lambda\|$. Thus the question about $\left\|\mathfrak{\Omega}_{T}\right\|$ as a mapping from $\mathfrak{A}$ to $\mathfrak{B}(H)$ naturally arises. In addition, Kadison, Lance, and Ringrose [2, Theorem 3.1] show that if $T=T^{*}$ and $\mathfrak{\Omega}_{T}$ maps $\mathfrak{X}$ into itself, then $\left\|\mathfrak{\Omega}_{T}\right\|=\inf \left\{2\left\|T-A^{\prime}\right\|: A^{\prime} \in \mathfrak{l}^{\prime}\right\}$. Our example will have $T$ self-adjoint, which shows that their hypothesis $\mathfrak{Q}_{T}(\mathfrak{U}) \subset \mathfrak{Q}$ is not inessential.

For our example, we take $H$ to be complex four-dimensional Hilbert spaces; elements of $H$ are to be thought of as column 4vectors, and elements of $\mathfrak{B}(H)$ as $4 \times 4$ matrices. We take $\mathfrak{A}$ to be the subalgebra of diagonal matrices, so $\mathfrak{X}^{\prime}=\mathfrak{X}$.

For $T$ we take the Hermitian matrix

$$
T=\frac{1}{12}\left|\begin{array}{lccc}
1 & -4 & \frac{1}{\sqrt{14}}(-5+6 i \sqrt{3}) & \frac{1}{\sqrt{14}}(-5-6 i \sqrt{3}) \\
-4 & 4 & -2 \sqrt{14} & -2 \sqrt{14} \\
\frac{1}{\sqrt{14}}(-5-6 i \sqrt{3}) & -2 \sqrt{14} & \frac{7}{2} & \frac{1}{14}(-95+12 i \sqrt{3}) \\
\frac{1}{\sqrt{14}}(-5+6 i \sqrt{3}) & -2 \sqrt{14} & \frac{1}{14}(-95-12 i \sqrt{3}) & \frac{7}{2}
\end{array}\right|
$$

$T$ is of the form $P-Q$ where $P$ and $Q$ are self-adjoint projections. The range of $P$ is two-dimensional and is spanned by the orthogonal unit vectors

$$
\begin{aligned}
& p^{(1)}=\frac{1}{2 \sqrt{3}}\left(1,-1+i \sqrt{3}, \frac{1}{\sqrt{14}}(4-5 i \sqrt{3}), \frac{1}{\sqrt{14}}(-2+i \sqrt{3})\right), \\
& p^{(2)}=\frac{1}{2 \sqrt{3}}\left(1,-1-i \sqrt{3}, \frac{1}{\sqrt{14}}(-2-i \sqrt{3}), \frac{1}{\sqrt{14}}(4+5 i \sqrt{3})\right) ;
\end{aligned}
$$

the range of $Q$ is one-dimensional and is spanned by the unit vector 


$$
q=\frac{1}{2 \sqrt{3}}\left(1,2, \sqrt{\frac{7}{2}}, \sqrt{\frac{7}{2}}\right) \text {. }
$$

First we show that $\left\|\mathfrak{\Omega}_{T}\right\|=\sup \{\|T X-X T\|: X \in \mathfrak{A},\|X\|=1\}<2$. As the unit sphere of $\mathfrak{A}$ is the convex hull of the unitary matrices in $\mathfrak{A}$, it suffices to consider $\|T X-X T\|$ only for diagonal unitary matrices $X$. As $T$ has norm 1 and any $X$ has norm 1 , $\|T X-X T\| \leqq 2$. Suppose then that there were an $X$ for which $\|T X-X T\|=2$ (since the set of $X$ under consideration is compact, the supremum defining $\mathfrak{Q}_{T}$ is attained). Then there must be a unit vector $u \in H$ for which $\|(T X-X T) u\|=2$, and since $T X$ and $X T$ are both of norm 1, we must have $\|T X u\|=1=\|X T u\|$; and since the norm of $H$ is strictly convex, we must have $T X u=-X T u$. Further, since $\|T u\|=1$, we must have $u=P u+Q u$. The next two relations are consequences of $T X u=-X T u$; start in the middle and work towards either end.

$$
\begin{aligned}
& P X P u+P X Q u=P X(P+Q) u=P X u \\
& \quad=P(P-Q) X u=P T X u=-P X T u \\
& =-P X P u+P X Q u,
\end{aligned}
$$

so $P X P u=0$;

$$
\begin{gathered}
-Q X P u-Q X Q u=-Q X u \\
=Q T X u=-Q X T u \\
=-Q X P u+Q X Q u ;
\end{gathered}
$$

so $Q X Q u=0$.

Next we observe that $X P u$ is in the range of $Q$ and $X Q u$ is in the range of $P$; for if one of these were not the case, we should have the strict inequality below:

$$
\begin{aligned}
1 & =\|u\|^{2}=\|Q u\|^{2}+\|P u\|^{2}=\|X Q u\|^{2}+\|X P u\|^{2} \\
& >\|P X Q u\|^{2}+\|Q X P u\|^{2} \\
& =\|P X(P+Q) u\|^{2}+\|Q X(P+Q) u\|^{2} \\
& =\|P X u\|^{2}+\|Q X u\|^{2}=\|T X u\|^{2} .
\end{aligned}
$$

But if $\left\|\mathfrak{\Omega}_{T}\right\|$ is to be 2 , we cannot allow $\|T X u\|<1$.

Since $\|X P u\|^{2}+\|X Q u\|^{2}=1$, not both of $X P u$ and $X Q u$ may be zero. Observe that operation on a vector by the diagonal unitary $X$ does not change the absolute value of any component. If $X P u \neq 0$, then $X P u$ is in the range of $Q$ and the conclusion we draw is that there must be a nonzero vector in the range of $p$ with moduli of components the same as that of $q$. If $X P u=0$, then $X Q u \neq 0$ and $X Q u$ is in the range of $P$; we draw the same conclusion. 
To finally reach the desired contradiction to the assumption $\left\|\mathfrak{Q}_{T}\right\|=2$, we need only show that no vector in the range of $p$ has components of the same modulus as $q$. Indeed, if there were, such a vector must be of the form $p=e^{i \beta}\left(\cos \Theta p^{(1)}+e^{i \phi} \sin \Theta p^{(2)}\right)$ for some real $\beta, \Theta, \Phi$. Equating the squares of the moduli of the first two components yields

$$
\begin{aligned}
1 & =\left|\cos \Theta+e^{i \Phi} \sin \Theta\right|^{2}=1+2 \cos \Theta \sin \Theta \cos \Phi, \\
4 & =\left|\cos \Theta(-1+i \sqrt{3})+e^{i \phi} \sin \Theta(-1-i \sqrt{3})\right|^{2} \\
& =4+8 \cos \Theta \sin \Theta \cos \left(\Phi+\frac{2 \pi}{3}\right) .
\end{aligned}
$$

Thus $\cos \Theta \sin \Theta=0$ and $p$ must be a multiple of $p^{(1)}$ or $p^{(2)}$; but neither of these has the moduli of their last two components the same as $q$.

Having demonstrated that $\left\|\mathfrak{Q}_{T}\right\|<2$, we show now that $\left\|T-A^{\prime}\right\| \geqq 1$ for every $A^{\prime} \in \mathfrak{X}^{\prime}$. As $\|T\|=1$, this is equivalent to showing that $\|T-D\| \geqq 1$ for every diagonal matrix $D$. Suppose, then, that there were a diagonal matrix $D$-with diagonal entries $d_{1}, d_{2}, d_{3}, d_{4}$-for which $\|T-D\|<1$. We may assume $D$ real, since $\|T-\operatorname{Re} D\|=\|\operatorname{Re}(T-D)\| \leqq$ $\|T-D\|<1$, where by $\operatorname{Re} A$ we mean $1 / 2\left(A+A^{*}\right)$.

Let $p$ be any unit vector in the range of $p$, and $q$ as before. Consider the inner product

$$
\left((T-D)\left(\cos \theta p+e^{i \phi} \sin \theta q\right),\left(\cos \theta p-e^{i \phi} \sin \theta q\right)\right) .
$$

This is equal to

$$
1-\left(D\left(\cos \Theta p+e^{i \Phi} \sin \Theta q\right),\left(\cos \Theta p-e^{i \oplus} \sin \Theta q\right)\right),
$$

but has absolute value less than 1 . Hence

$$
\operatorname{Re}\left(D\left(\cos \Theta p+e^{i \Phi} \sin \Theta q\right),\left(\cos \Theta p-e^{i \Phi} \sin \Theta q\right)\right)>0,
$$

for any choice of $p, \Theta$, and $\Phi$. The choices $\Theta=0, p=p^{(1)}$, and $p=p^{(2)}$ give

$$
\begin{aligned}
& \left(d_{1}+4 d_{2}+\frac{13}{2} d_{3}+\frac{1}{2} d_{4}\right)>0, \\
& \left(d_{1}+4 d_{2}+\frac{1}{2} d_{3}+\frac{13}{2} d_{4}\right)>0,
\end{aligned}
$$

and hence

$$
\left(d_{1}+4 d_{2}+\frac{7}{2} d_{3}+\frac{7}{2} d_{4}\right)>0 .
$$

But the choice $\Theta=\pi / 2$ gives 


$$
-\left(d_{1}+4 d_{2}+\frac{7}{2} d_{3}+\frac{7}{2} d_{4}\right)>0
$$

This incompatibility is a contradiction to $\|T-D\|<1$.

The reader will observe the similarity with Example 5.5 of [3]. In spirit, we have the logarithmic analogue of the problem of conditioning matrices. One can ascertain conditions that $\left\|T-A^{\prime}\right\| \geqq\|T\|$ for all $A^{\prime} \in \mathfrak{X}^{\prime}$ by consideration of the norms $\|T\|_{p}=\left[\operatorname{trace}\left(T^{*} T\right)^{p / 2}\right]^{1 / p}$ as $p \rightarrow \infty$, as in [4, Lemma 4.7, Theorem 4.8] or, more generally, [5, $\S 6]$. For $T$ self-adjoint, the relevant condition to have $\left\|T-A^{\prime}\right\| \geqq\|T\|$ for all diagonal $A^{\prime}$ is that both numbers - $\|T\|$ and $\|T\|$ are eigenvalues of $T$ and that the spectral projections associated with these eigenvalues have proportional diagonals. Conditions involving suprema of norms over the group of diagonal unitaries are related to the moduli of components of certain vectors; see [4, Theorem 5.4], as well as $[1,2]$. Finally, we note that for the analogous problem of conditioning matrices, examples such as we have constructed are not available in $3 \times 3$ matrices, nor with $4 \times 4$ real matrices.

\section{REFERENCES}

1. G. E. Forsythe and E. G. Straus, On best conditioned matrices, Proc. Amer. Math. Soc., 6 (1955), 340-345.

2. G. H. Golub and J. M. Varah, On a characterization of the best $l_{2}$ scaling of a matrix, To appear in SIAM J. Numer. Anal.

3. R. V. Kadison, E. C. Lance, and J. R. Ringrose, Derivations and automorphisms of operator algebras, II. J. Funct. Anal., 1 (1967), 204-221.

4. C. Me Carthy and G. Strang, Optimal conditioning of matrices, SIAM J. Numer. Anal., 10 (1973), 370-388.

5. C. Mc Carthy, Optimal conditioning of operators on Hilbert space, Functional Analysis (Proc. symposium, Monterey, California, 1969). Academic Press, (1970), 107-125. 6. J. G. Stampfli, The norm of a derivation, Pacific J. Math., 33 (1970), 131-141.

Received May 2, 1973. Supported in part by NSF GP28933. I should like to thank the Department of Mathematics, University of Newcastle upon Tyne, for their hospitality and encouragement in this work.

University of MinNesota

AND

Chalmers Tekniska Högskola 


\section{PACIFIC JOURNAL OF MATHEMATICS}

\section{EDITORS}

RICHARD ARENS (Managing Editor)

University of California

Los Angeles, California 90024

\section{J. DUGUNDJI}

Department of Mathematics University of Southern California Los Angeles, California 90007

D. Gilbarg and J. Milgram

Stanford University

Stanford, California 94305

University of Washington
Seattle, Washington 98105

ASSOCIATE EDITORS
E. F, BECKENBACH
B. H. NEUMANN
F. WOLF
K. Yoshida

\section{SUPPORTING INSTITUTIONS}

\author{
UNIVERSITY OF BRITISH COLUMBIA \\ CALIFORNIA INSTITUTE OF TECHNOLOGY \\ UNIVERSITY OF CALIFORNIA \\ MONTANA STATE UNIVERSITY \\ UNIVERSITY OF NEVADA \\ NEW MEXICO STATE UNIVERSITY \\ OREGON STATE UNIVERSITY \\ UNIVERSITY OF OREGON \\ OSAKA UNIVERSITY
}

\author{
UNIVERSITY OF SOUTHERN CALIFORNIA \\ STANFORD UNIVERSITY \\ UNIVERSITY OF TOKYO \\ UNIVERSITY OF UTAH \\ WASHINGTON STATE UNIVERSITY \\ UNIVERSITY OF WASHINGTON \\ * * * * \\ AMERICAN MATHEMATICAL SOCIETY \\ NAVAL WEAPONS CENTER
}

The Supporting Institutions listed above contribute to the cost of publication of this Journal, but they are not owners or publishers and have no responsibility for its content or policies.

Mathematical papers intended for publication in the Pacific Journal of Mathematics should be in typed form or offset-reproduced, (not dittoed), double spaced with large margins. Underline Greek letters in red, German in green, and script in blue. The first paragraph or two must be capable of being used separately as a synopsis of the entire paper. Items of the bibliography should not be cited there unless absolutely necessary, in which case they must be identified by author and Journal, rather than by item number. Manuscripts, in duplicate if possible, may be sent to any one of the four editors. Please classify according to the scheme of Math. Rev. Index to Vol. 39. All other communications to the editors should be addressed to the managing editor, or Elaine Barth, University of California, Los Angeles, California, 90024.

100 reprints are provided free for each article, only if page charges have been substantially paid. Additional copies may be obtained at cost in multiples of 50 .

The Pacific of Journal Mathematics is issued monthly as of January 1966. Regular subscription rate: $\$ 72.00$ a year (6 Vols., 12 issues). Special rate: $\$ 36.00$ a year to individual members of supporting institutions.

Subscriptions, orders for back numbers, and changes of address should be sent to Pacific Journal of Mathematics, 103 Highland Boulevard, Berkeley, California, 94708.

PUBLISHED BY PACIFIC JOURNAL OF MATHEMATICS, A NON-PROFIT CORPORATION

Printed at Kokusai Bunken Insatsusha (International Academic Printing Co., Ltd.), 270, 3-chome Totsuka-cho, Shinjuku-ku, Tokyo 160, Japan.

Copyright (C) 1973 by Pacific Journal of Mathematics Manufactured and first issued in Japan 


\section{Pacific Journal of Mathematics}

\section{Vol. 53, No. $2 \quad$ April, 1974}

Kenneth Abernethy, On characterizing certain classses of first countable spaces by

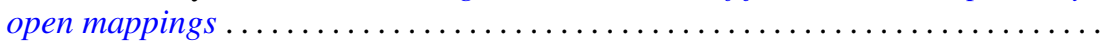

Ross A. Beaumont and Donald Lawver, Strongly semisimple abelian groups .......

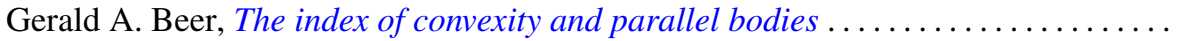

Victor P. Camillo and Kent Ralph Fuller, On Loewy length of rings ..............

Stephen LaVern Campbell, Linear operators for which $T^{*} T$ and $T T^{*}$ commute.

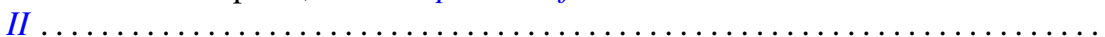

Charles Kam-Tai Chui and Philip Wesley Smith, Characterization of a function by

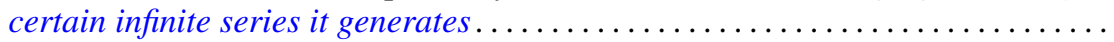

Allan L. Edelson, Conjugations on stably almost complex manifolds . ...........

Patrick John Fleury, Hollow modules and local endomorphism rings . . ..........

Jack Tilden Goodykoontz, Jr., Connectedness im kleinen and local connectedness in

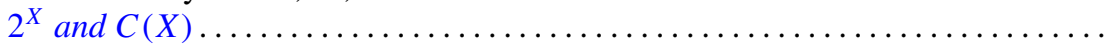

Robert Edward Jamison, II, Functional representation of algebraic intervals .......

Athanassios G. Kartsatos, Nonzero solutions to boundary value problems for

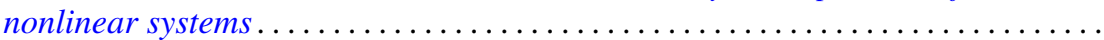

Soon-Kyu Kim, Dennis McGavran and Jingyal Pak, Torus group actions on simply

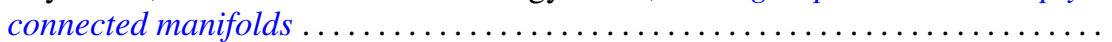

David Anthony Klarner and R. Rado, Arithmetic properties of certain recursively

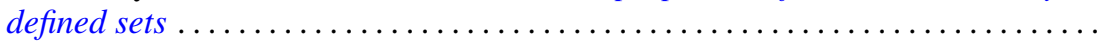

Ray Alden Kunze, On the Frobenius reciprocity theorem for square-integrable

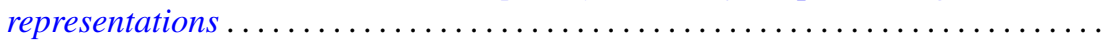

John Lagnese, Existence, uniqueness and limiting behavior of solutions of a class of differential equations in Banach space...

Teck Cheong Lim, A fixed point theorem for families on nonexpansive mappings Lewis Lum, A quasi order characterization of smooth continua

Andy R. Magid, Principal homogeneous spaces and Galois extensions . .

Charles Alan McCarthy, The norm of a certain derivation ..... . .

Louise Elizabeth Moser, On the impossibility of obtaining $S^{2} \times S^{1}$ by elementary surgery along a knot. .

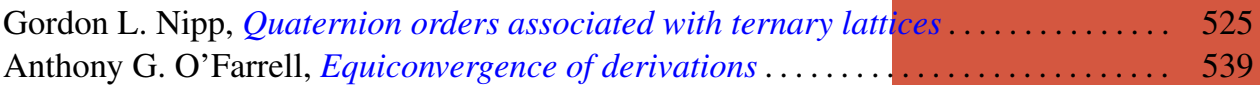

Dorte Olesen, Derivations of $A W^{*}$-algebras are inner . . . . . . . . . . . . . . . 555

Dorte Olesen and Gert Kjærgaard Pedersen, Derivations of $C^{*}$-algebras have

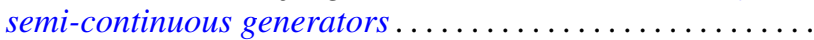

Duane O’Neill, On conjugation cobordism.

Chull Park and S. R. Paranjape, Probabilities of Wiener paths crossing differentiable

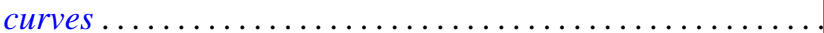

Edward Ralph Rozema, Almost Chebyshev subspaces of $L^{1}(\mu$;

Lesley Millman Sibner and Robert Jules Sibner, A note on the Atiyah-Bott fixed

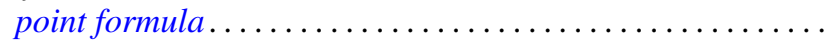

Betty Salzberg Stark, Irreducible subgroups of orthogonal groups generated by

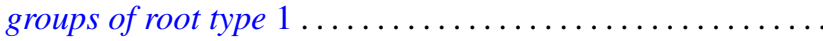

N. Stavrakas, A note on starshaped sets, $(k)$-extreme points and the half ray

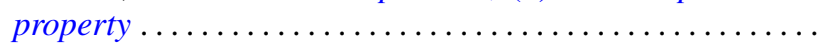

Carl E. Swenson, Direct sum subset decompositions of $Z \ldots \ldots$ 